\title{
Exploring the association between feeding habits, non-nutritive sucking habits, and malocclusions in the deciduous dentition
}

\author{
Gabriela Mesquita Lopes-Freire ${ }^{1 *}$, Abel Belizario Cahuana Cárdenas², José Enrique Espasa Suarez de Deza', \\ Josep Maria Ustrell-Torrent ${ }^{3}$, Luciana Butini Oliveira ${ }^{4}$ and Joan Ramon Boj Quesada JR ${ }^{1}$
}

\begin{abstract}
Background: This study aimed to explore the association between feeding habits, non-nutritive sucking habits, and malocclusions in deciduous dentition.

Methods: A cross-sectional observational survey was carried out in 275 children aged 3 to 6 years and included clinical evaluations of malocclusions and structured interviews. Statistical significance for the association between feeding habits and the development of malocclusion was determined using chi-square and Fisher's exact tests. In addition, odds ratio (OR) calculations were used for intergroup comparisons. Controlling for confounders was adjusted by excluding children with non-nutritive sucking habits.
\end{abstract}

Results: The results indicated that there were no significant relationships between exclusive breastfeeding or bottlefeeding and the presence of any type of malocclusion $(p>0.05)$. There was also no significant association between breastfeeding or bottlefeeding duration and malocclusion ( $p>0.05$ ). In addition, it was observed that exclusive breastfeeding had a protective effect and diminished the risk of acquiring non-nutritive sucking habits ( $p=0.001)$.

Conclusions: There was no association between feeding habits and malocclusions in the deciduous dentition in this sample of children. Exclusive breastfeeding reduced the risk of acquiring non-nutritive sucking habits.

Keywords: Breastfeeding, Bottlefeeding, Malocclusion

\section{Background}

The sucking habits of infants are described in the literature as being of two types: non-nutritive and nutritive. Finger sucking, thumb sucking, and sucking on a pacifier (dummy, comforter) are considered non-nutritive sucking habits. Breastfeeding and bottlefeeding are considered nutritive sucking habits.

Several studies reported the association between feeding habits (breastfeeding and/or bottlefeeding), nonnutritive habits, and malocclusion [1-8]. The findings on associations between types and duration of feeding habits and malocclusion are conflicting. Moreover, confounder variables (presence of non-nutritive habits) were not performed in many previous studies.

The advantages afforded by breastfeeding have been reported in the literature and include the well-established

\footnotetext{
*Correspondence: gabimlopes@gmail.com

${ }^{1}$ Department of Paediatric Dentistry, Faculty of Dentistry, University of

Barcelona Hospitalet de Llobregat, Barcelona, Spain

Full list of author information is available at the end of the article
}

immunological and psychological benefits, adequate weight gain for the baby, and the correct development of the oral structures involved in the action of sucking. A prospective birth cohort study from Brazil concluded that breastfeeding is associated with improved performance in intelligence tests 30 years later, and might have an important effect in real life, by increasing educational attainment and income in adulthood [9]. Previous studies showed that prolonged breastfeeding may have a protective effect on the development of malocclusions [1-7]. However, a recent systematic review of cohort studies concluded that the scientific evidence could not confirm the types of malocclusion associated with bottlefeeding or a proper period for breastfeeding in order to protect against malocclusion [10].

Observational surveys provide important information about the feeding practices and malocclusion status and contribute to the development of awareness among professionals as well as among the target population. It is
照 Springer

(c) 2015 Lopes-Freire et al. Open Access This article is distributed under the terms of the Creative Commons Attribution 4.0 International License (http://creativecommons.org/licenses/by/4.0/), which permits unrestricted use, distribution, and reproduction in any medium, provided you give appropriate credit to the original author(s) and the source, provide a link to the Creative Commons license, and indicate if changes were made. 
important to investigate the presence of malocclusion in deciduous dentition because it is a public dental health problem in children in Spain. In addition, current recommendations for discontinuing non-nutritive sucking habits may be optimal in preventing habit-related malocclusions at the end of the primary dentition stage $[11,12]$.

Therefore, the aim of this study was to explore the association between feeding habits, non-nutritive sucking habits, and malocclusions in the deciduous dentition in a population of Spanish children.

\section{Methods}

This study was approved by the Research Ethics Committee of the University of Barcelona and the Children Hospital of Barcelona and conducted in a day care center, CAP, Montcada i Reixac. The participants' legal guardians gave positive consent on the day of the clinical examination.

A cross-sectional observational survey was carried out on boys and girls aged 3 to 6 years and included clinical evaluations of malocclusions and structured interviews.

All the children in the study met the inclusion criteria which included children of both genders aged 3 to 6 years; children exclusively in the deciduous dentition phase; agreement to participate in the clinical exam; all the normal numbers, sizes, and shapes of deciduous teeth; no major tooth destruction or reconstruction; children with no systemic diseases and/or neurological diseases; and parental questionnaires about the child's habits.

Children were excluded from the study if their parents did not agree to their participation, they have syndromes or systemic problems affecting craniofacial growth, they have the presence of at least one permanent tooth, they have loss of mesial-distal diameter due to caries, and they have previous orthodontic treatment.

All clinical exams were performed by an experienced examiner, a PhD student (GMLF) who had previous experience in cross-sectional data. The child remained seated on a chair in front of the examiner. The examinations were performed under artificial light, using latex gloves and a disposable spatula. The clinical exam was performed with the aid of a disposable tongue depressor source. To ensure that natural occlusion was evaluated, the child was asked to open and close his/her mouth several times and to swallow saliva before the examination began. When necessary, the mandible was gently guided towards centric occlusion by the examiner.

The outcomes related to the children's dental arch characteristics were examined in the three dimensions with the following criteria.

The transverse relation was measured by direct inspection in the presence of posterior crossbite or if the absence was considered normal occlusion. One of five separate relationships was recorded considering the following categories: normal relationship; posterior unilateral crossbite left side; posterior unilateral crossbite right side; bilateral posterior crossbite-both hemi-arches; and just one tooth was crossed. Posterior crossbite is considered present when, in occlusion, one or more of the maxillary deciduous canine or molars occluded lingual to the buccal cusps of the opposing mandibular teeth. Upper midline shift was registered if the midline was displaced by at least $1 \mathrm{~mm}$. In addition, midline deviation data was also collected and the distance between the upper and lower midlines in the frontal plane was considered.

The vertical relation (relationship of incisors) was measured by direct inspection: one of three separate relationships was recorded in normal, anterior open bite, and overbite. Overbite was obtained by measuring the vertical distance between the upper and lower central incisor edges with the teeth in occlusion [13]. This distance was considered normal when the upper incisor covered the lower up to $3 \mathrm{~mm}$ and overbite for values greater than $3 \mathrm{~mm}$. When there was no overlap between the upper and lower incisors, with a minimum space of $1 \mathrm{~mm}$ between both incisal edges, it was considered anterior open bite [14].

The sagittal interarch relationship was classified according to the deciduous canine relationship as angle class I, class II, or class III, with class I considered normal occlusion, class I canine and molars bilateral, or class I canine and molars unilateral, and class II or class III considered altered: class II bilateral, class II 1 (increased overjet), class II 2 (without overjet), class II subdivision (I o III), class II unilateral, others with no classification, and class III or anterior crossbite.

A questionnaire in the form of a structured interview was applied with mothers or guardians in order to find out about nutritive sucking habits (breastfeeding and bottlefeeding), non-nutritive sucking habits (pacifiers and finger sucking), and the presence of malocclusions. The data collected included the presence and the duration of non-nutritive sucking habits and, if the child had sucking, any type of non-nutritive sucking habits: pacifier-sucking habit and digit sucking.

Data analyses were performed using SPSS software 22.0. Data analysis included descriptive statistics (frequency distribution). Statistical significance for the association between the non-nutritive sucking habits and the development of malocclusion was determined using chi-square, and Fisher's exact tests with odds ratio (OR) calculations were used for intergroup comparisons. Children with nonnutritive sucking habits were excluded from the analysis. The level of significance was set at $5 \%$.

\section{Results}

The sample consisted of 275 children aged 3 to 6 years; $144(52.4 \%)$ were males and 131 (47.6\%) were females. Of 275 children, only 28 children were exclusively 
breastfeeding, and 247 children were breastfeeding/ bottlefeeding. The presence of non-nutritive sucking habits was observed in 224 children (81.5\%).

The results presented in Table 1 indicated that there was no significant relationship between exclusive breastfeeding and the presence of any type of malocclusion OR 1.37 (confidence interval (CI) 0.34-5.51, $p=0.739$ ). The results also indicated that there was no significant relationship between bottlefeeding and the presence of any type of malocclusion OR 1.35 (CI $0.31-5.96, p=$ 0.716 ) (Table 2). In addition, there was no significant association between breastfeeding or bottlefeeding duration and malocclusion (Tables 3 and 4).

It was observed in Table 5 that exclusive breastfeeding had a protective effect and diminished the risk of acquiring non-nutritive sucking habits OR 0.18 (CI 0.07-0.40, $p=0.001)$. Exclusive breastfeeding may have reduced the risk of pacifier use OR 0.24 (CI 0.11-0.52, $p=0.001$ ). However, there was no significant association between exclusive breastfeeding and finger-sucking habit $(p=0.374)$. In addition, there was no significant association with intensity and duration of non-nutritive sucking habits.

\section{Discussion}

The results in the present study indicated that there was no significant relationship between exclusive breastfeeding and the presence of any type of malocclusion. The results also indicated that there was no significant relationship between bottlefeeding and the presence of any type of malocclusion. However, it was observed that exclusive breastfeeding had a protective effect and diminished the risk of acquiring non-nutritive sucking habits.

At present, there is no consensus related to the association between feeding habits and malocclusion. Previous studies have reported that there was influence of feeding patterns on the development of malocclusion $[1-8,15-20]$. According to some authors, breastfeeding and bottlefeeding involve different orofacial muscles, which possible have different effects on the harmonic growth of maxilla and dental arches. Meanwhile, breathing, swallowing, and mastication should be developed in harmony, and differences exist in the learning of the coordinated movement between breastfeeding and bottlefeeding children [18].

On the other hand, some studies did not found this association [11, 21, 22]. Some authors observed among children with minimal non-nutritive habits that those who breastfed had similar dental arch parameters and occlusal characteristics as those with shorter duration of breastfeeding or no breastfeeding [11]. A possible explanation is that the effects of breastfeeding on dental arch development are difficult to assess because it is not easy to separate these effects from those non-nutritive sucking behaviors. This result is because most breastfed children also engaged in at least some non-nutritive sucking.

The finding that exclusive breastfeeding had a protective effect and diminished the risk of acquiring non-nutritive sucking habits is in agreement with previous studies [6, 23-26]. In this investigation, thumb sucking has the same result with breastfeeding and bottlefeeding but the use of a pacifier was more utilized for bottlefeeding children. It is important to emphasize that breastfeeding

Table 1 Relationship between exclusive breastfeeding and malocclusion

\begin{tabular}{|c|c|c|c|c|c|c|c|c|}
\hline & & \multicolumn{7}{|c|}{ Exclusive breastfeeding } \\
\hline & & \multicolumn{2}{|l|}{ No } & \multicolumn{2}{|l|}{ Yes } & \multirow[b]{2}{*}{ OR } & \multirow[b]{2}{*}{ Cl $95 \%$} & \multirow[b]{2}{*}{$p$ value } \\
\hline & & N & $\%$ & N & $\%$ & & & \\
\hline \multirow[t]{3}{*}{ Transversal relationship } & Malocclusion in transversal relationship & 3 & 8.1 & 0 & 0.0 & Infinity & NA & 0.552 \\
\hline & Normal & 34 & 91.9 & 14 & 100.0 & & & \\
\hline & Total & 37 & 100.0 & 14 & 100.0 & & & \\
\hline \multirow[t]{3}{*}{ Midline deviation } & Malocclusion in midline & 4 & 11.1 & 1 & 7.1 & 0.54 & $0.11-2.76$ & 0.662 \\
\hline & Normal & 32 & 88.9 & 13 & 92.9 & & & \\
\hline & Total & 36 & 100.0 & 14 & 100.0 & & & \\
\hline \multirow[t]{3}{*}{ Vertical relationship } & Malocclusion in vertical relationship & 6 & 16.2 & 3 & 21.4 & 0.71 & $0.15-3.33$ & 0.692 \\
\hline & Normal & 31 & 83.8 & 11 & 78.6 & & & \\
\hline & Total & 37 & 100.0 & 14 & 100.0 & & & \\
\hline \multirow[t]{3}{*}{ Sagittal relationship } & Malocclusion in sagittal relationship & 10 & 30.3 & 2 & 16.7 & 2.17 & $0.401-11.76$ & 0.466 \\
\hline & Normal & 23 & 69.7 & 10 & 83.3 & & & \\
\hline & Total & 33 & 100.0 & 12 & 100.0 & & & \\
\hline \multirow[t]{3}{*}{ Presence of malocclusion } & Any type of malocclusion & 13 & 40.6 & 4 & 33.3 & 1.37 & $0.34-5.51$ & 0.739 \\
\hline & Normal & 19 & 59.4 & 8 & 66.7 & & & \\
\hline & Total & 32 & 100.0 & 12 & 100.0 & & & \\
\hline
\end{tabular}


Table 2 Relationship between exclusive bottlefeeding and malocclusion

\begin{tabular}{|c|c|c|c|c|c|c|c|c|}
\hline & & \multicolumn{7}{|c|}{ Exclusive bottlefeeding } \\
\hline & & \multicolumn{2}{|c|}{ Yes } & \multicolumn{2}{|l|}{ No } & \multirow[b]{2}{*}{ OR } & \multirow[b]{2}{*}{ Cl $95 \%$} & \multirow[b]{2}{*}{$p$ value } \\
\hline & & N & $\%$ & N & $\%$ & & & \\
\hline \multirow[t]{3}{*}{ Transversal relationship } & Malocclusion in transversal relationship & 1 & 7.7 & 2 & 5.3 & 1.50 & $0.12-18.05$ & 1.00 \\
\hline & Normal & 12 & 92.3 & 36 & 94.7 & & & \\
\hline & Total & 13 & 100.0 & 38 & 100.0 & & & \\
\hline \multirow[t]{3}{*}{ Midline deviation } & Malocclusion in midline & 1 & 8.3 & 4 & 10.5 & 0.77 & $0.08-7.66$ & 1.00 \\
\hline & Normal & 11 & 91.7 & 34 & 89.5 & & & \\
\hline & Total & 12 & 100.0 & 38 & 100.0 & & & \\
\hline \multirow[t]{3}{*}{ Vertical relationship } & Malocclusion in vertical relationship & 1 & 7.7 & 8 & 21.1 & 0.31 & $0.04-2.78$ & 0.42 \\
\hline & Normal & 12 & 92.3 & 30 & 78.9 & & & \\
\hline & Total & 13 & 100.0 & 38 & 100.0 & & & \\
\hline \multirow[t]{3}{*}{ Sagittal relationship } & Malocclusion in sagittal relationship & 3 & 30.0 & 9 & 25.7 & 1.24 & $0.26-5.84$ & 1.00 \\
\hline & Normal & 7 & 70.0 & 26 & 74.3 & & & \\
\hline & Total & 10 & 100.0 & 35 & 100.0 & & & \\
\hline \multirow[t]{3}{*}{ Presence of malocclusion } & Any type of malocclusion & 4 & 44.4 & 13 & 37.1 & 1.35 & $0.31-5.96$ & 0.716 \\
\hline & Normal & 5 & 55.6 & 22 & 62.9 & & & \\
\hline & Total & 9 & 100.0 & 35 & 100.0 & & & \\
\hline
\end{tabular}

seems to have non-nutritive protective impact. If the parents refuse to give the pacifier, the result may be different and thumb-sucking habit is something that children choose or need to do without the factor of parents giving the artifact to stimulate non-nutritive sucking.

A previous study investigated the influence of thumb sucking and pacifier use on breastfeeding patterns in exclusively breastfed infants, on the duration of exclusive breastfeeding, and on the total breastfeeding duration. The authors concluded that thumb sucking was clearly not related to the negative effects on the pattern and duration of breastfeeding. The possible negative effects of pacifier use on breastfeeding pattern and duration were related to frequency. In addition, occasional pacifier use was not found to have any negative effect on breastfeeding duration [27].

Table 3 Relationship between bottlefeeding duration and malocclusion

\begin{tabular}{|c|c|c|c|c|c|c|c|c|}
\hline & & \multicolumn{7}{|c|}{ Bottlefeeding duration } \\
\hline & & \multicolumn{2}{|c|}{$>6-12$ months } & \multicolumn{2}{|c|}{$>12$ months } & \multirow[b]{2}{*}{ OR } & \multirow[b]{2}{*}{ Cl $95 \%$} & \multirow[b]{2}{*}{$p$ value } \\
\hline & & N & $\%$ & N & $\%$ & & & \\
\hline \multirow[t]{3}{*}{ Transversal relationship } & Malocclusion in transversal relationship & 0 & 0.0 & 3 & 10.0 & 0 & NA & 1.00 \\
\hline & Normal & 4 & 100.0 & 27 & 90.0 & & & \\
\hline & Total & 4 & 100.0 & 30 & 100.0 & & & \\
\hline \multirow[t]{3}{*}{ Midline deviation } & Malocclusion in midline & 1 & 33.3 & 3 & 10.0 & 4.5 & $0.31-65.67$ & 0.33 \\
\hline & Normal & 2 & 66.7 & 27 & 90.0 & & & \\
\hline & Total & 3 & 100.0 & 30 & 100.0 & & & \\
\hline \multirow[t]{3}{*}{ Vertical relationship } & Malocclusion in vertical relationship & 1 & 25.0 & 5 & 16.7 & 1.67 & $0.14-19.48$ & 1.00 \\
\hline & Normal & 3 & 75.0 & 25 & 83.3 & & & \\
\hline & Total & 4 & 100.0 & 30 & 100.0 & & & \\
\hline \multirow[t]{3}{*}{ Sagittal relationship } & Malocclusion in sagittal relationship & 2 & 50.0 & 8 & 30.8 & 2.25 & $0.27-18.93$ & 0.584 \\
\hline & Normal & 2 & 50.0 & 18 & 69.2 & & & \\
\hline & Total & 4 & 100.0 & 26 & 100.0 & & & \\
\hline \multirow[t]{3}{*}{ Presence of malocclusion } & Any type of malocclusion & 2 & 66.7 & 11 & 42.3 & 2.73 & $0.23-34.01$ & 0.573 \\
\hline & Normal & 1 & 33.3 & 15 & 57.7 & & & \\
\hline & Total & 3 & 100.0 & 26 & 100.0 & & & \\
\hline
\end{tabular}


Table 4 Relationship between breastfeeding duration and malocclusion

\begin{tabular}{|c|c|c|c|c|c|c|c|c|}
\hline & & \multicolumn{7}{|c|}{ Breastfeeding duration } \\
\hline & & \multicolumn{2}{|c|}{$<6$ months } & \multicolumn{2}{|c|}{$>12$ months } & \multirow[b]{2}{*}{ OR } & \multirow[b]{2}{*}{ Cl $95 \%$} & \multirow[b]{2}{*}{$p$ value } \\
\hline & & N & $\%$ & N & $\%$ & & & \\
\hline \multirow[t]{3}{*}{ Transversal relationship } & Malocclusion in transversal relationship & 2 & 11.1 & 0 & 0.0 & Infinity & NA & 0.229 \\
\hline & Normal & 16 & 88.9 & 19 & 100.0 & & & \\
\hline & Total & 18 & 100.0 & 19 & 100.0 & & & \\
\hline \multirow[t]{3}{*}{ Midline deviation } & Malocclusion in midline & 2 & 11.1 & 2 & 10.5 & 1.06 & $0.13-8.47$ & 1.00 \\
\hline & Normal & 16 & 88.9 & 17 & 89.5 & & & \\
\hline & Total & 18 & 100.0 & 19 & 100.0 & & & \\
\hline \multirow[t]{3}{*}{ Vertical relationship } & Malocclusion in vertical relationship & 4 & 22.2 & 4 & 21.1 & 1.07 & $0.22-5.13$ & 1.00 \\
\hline & Normal & 14 & 77.8 & 15 & 78.9 & & & \\
\hline & Total & 18 & 100.0 & 19 & 100.0 & & & \\
\hline \multirow[t]{3}{*}{ Sagittal relationship } & Malocclusion in sagittal relationship & 5 & 27.8 & 4 & 25.0 & 1.15 & $0.25-5.33$ & 1.00 \\
\hline & Normal & 13 & 72.2 & 12 & 75.0 & & & \\
\hline & Total & 18 & 100.0 & 16 & 100.0 & & & \\
\hline \multirow[t]{3}{*}{ Presence of malocclusion } & Any type of malocclusion & 6 & 33.3 & 7 & 43.8 & 0.64 & $0.16-2.58$ & 0.725 \\
\hline & Normal & 12 & 66.7 & 9 & 56.3 & & & \\
\hline & Total & 18 & 100.0 & 16 & 100.0 & & & \\
\hline
\end{tabular}

In offering an explanation for the relationships between breastfeeding and the risk of acquiring non-nutritive sucking habits, some potential limitations of this study should be taken into account. First, no cause-effect relationship can be deduced from a cross-sectional design study such as this one. Longitudinal designs (cohort studies) would increase the knowledge on this subject.

Moreover, there is much controversy surrounding the issue of diagnosis of malocclusions due to the inexistence of a universally accepted index. Comparisons between studies should be interpreted with caution due to the lack of uniformity in sample selection, diagnostic criteria, and classifications and age groups.

A positive attribute of this study was that children with non-nutritive sucking habits were excluded from the analysis. Recently, a systematic review also reported that substantial methodological and clinical heterogeneity was found among the studies in this issue. The

Table 5 Relationship between exclusive breastfeeding and non-nutritive sucking habits

\begin{tabular}{|c|c|c|c|c|c|c|c|c|c|c|}
\hline & & \multicolumn{9}{|c|}{ Exclusive breastfeeding } \\
\hline & & \multicolumn{2}{|c|}{ Yes } & \multicolumn{2}{|l|}{ No } & \multicolumn{2}{|c|}{ Total } & \multirow[b]{2}{*}{ OR } & \multirow[b]{2}{*}{ Cl $95 \%$} & \multirow[b]{2}{*}{$p$ value } \\
\hline & & $\bar{N}$ & $\%$ & $\bar{N}$ & $\%$ & $\bar{N}$ & $\%$ & & & \\
\hline \multirow[t]{3}{*}{ Pacifier } & Yes & 14 & 50.0 & 200 & 81.0 & 214 & 77.8 & 0.24 & $0.11-0.52$ & 0.001 \\
\hline & No & 14 & 50.0 & 47 & 19.0 & 61 & 22.2 & & & \\
\hline & Total & 28 & 100.0 & 247 & 100.0 & 275 & 100.0 & & & \\
\hline \multirow[t]{3}{*}{ Finger sucking } & Yes & 0 & 0.0 & 14 & 5.7 & 14 & 5.1 & 0 & NA & 0.374 \\
\hline & No & 28 & 100.0 & 233 & 94.3 & 261 & 94.9 & & & \\
\hline & Total & 28 & 100.0 & 247 & 100.0 & 275 & 100.0 & & & \\
\hline \multirow[t]{3}{*}{ Duration } & $>12$ months & 14 & 100.0 & 204 & 97.1 & 218 & 97.3 & Infinity & NA & 1 \\
\hline & $<12$ months & 0 & 0.0 & 6 & 2.9 & 6 & 2.7 & & & \\
\hline & Total & 14 & 100.0 & 210 & 100.0 & 224 & 100.0 & & & \\
\hline \multirow[t]{2}{*}{ Intensity } & Moderate or high use & 5 & 41.7 & 132 & 64.4 & 137 & 63.1 & 0.39 & $0.12-1.29$ & 0.131 \\
\hline & Low use & 7 & 58.3 & 73 & 35.6 & 80 & 36.9 & & & \\
\hline \multirow[t]{3}{*}{ Non-nutritive sucking habits } & Yes & 14 & 50.0 & 210 & 85.0 & 224 & 81.5 & 0.18 & $0.07-0.40$ & 0.001 \\
\hline & No & 14 & 50.0 & 37 & 15.0 & 51 & 18.5 & & & \\
\hline & Total & 28 & 100.0 & 247 & 100.0 & 275 & 100.0 & & & \\
\hline
\end{tabular}


major limitation is the failure to report controlling for confounder variables. Pacifier use and thumb sucking are confounder variables, since it is not possible to determine whether malocclusion was caused by bottlefeeding or pacifier/thumb sucking. The absence of controlling for confounders may have led to bias results in previous studies [10].

Some authors emphasized that breastfeeding alone seems not to be directly associated with malocclusions, but it may have a synergetic effect with parafunctional oral habits on the development of occlusofacial problems [28]. They also reinforced the arguments for the prevention of bad oral habits, especially among children who have not been fed at their mother's breast or were breastfed for a short period.

Despite the multiple benefits of maternal breastfeeding, artificial feeding is widely used and may have contributed to the high rates of pacifier use and other harmful habits. Exclusive breastfeeding for at least 6 months of age is still the best recommendation to benefit children regarding their systemic health and harmonic craniofacial growth [10].

\section{Conclusions}

In conclusion, there was no association between feeding habits and malocclusions in the deciduous dentition in this sample of children. Exclusive breastfeeding reduced the risk of acquiring non-nutritive sucking habits.

\section{Competing interest}

The authors declare that they have no competing interests.

\section{Authors' contributions}

GMLF participated in all phases of the study and drafting the manuscript. ABCC participated in the data collection. JEESD, JMUT, and JRBQ participated in the design, compiled the results, and supervised the research. LBO collaborated with the writing and reviewing of the text. All the authors read and approved the final manuscript.

\section{Acknowledgements}

The authors also thank the University of Barcelona, the Children Hospital of Barcelona, CAP, Montcada i Reixac, and the children and their mothers for their cooperation in carrying out this study.

\section{Author details}

'Department of Paediatric Dentistry, Faculty of Dentistry, University of Barcelona Hospitalet de Llobregat, Barcelona, Spain. ${ }^{2}$ Pediatric Dentistry and Orthodontic Service, Hospital Sant Joan de Déu, Barcelona, Spain. ${ }^{3}$ Department of Orthodontics, Oral Health and Masticatory System Group (Bellvitge Biomedical Research Institute) IDIBELL, Faculty of Dentistry, L'Hospitalet, Barcelona, Spain. ${ }^{4}$ Department of Pediatric Dentistry, School of Dentistry, Faculdade São Leopoldo Mandic, Campinas, SP, Brazil.

Received: 16 September 2015 Accepted: 6 December 2015 Published online: 18 December 2015

\section{References}

1. Peres KG, Barros AJ, Peres MA, Victora CG. Effects of breastfeeding and sucking habits on malocclusion in a birth cohort study. Rev Saude Publica. 2007:41(3):343-50.

2. Kobayashi HM, Scavone Jr H, Ferreira Rl, Garib DG. Relationship between breastfeeding duration and prevalence of posterior crossbite in the deciduous dentition. Am J Orthod Dentofacial Orthop. 2010;137(1):54-8.
3. Sanchez-Molins M, Grau Carbó J, Lischeid Gaig C, Ustrell Torrent JM Comparative study of the craniofacial growth depending on the type of lactation received. Eur J Paediatr Dent. 2010;11(2):87-92.

4. Romero CC, Scavone-Junior H, Garib DG, Cotrim-Ferreira FA, Ferreira RI. Breastfeeding and non-nutritive sucking patterns related to the prevalence of anterior open bite in primary dentition. J Appl Oral Sci. 2011;19(2):161-8.

5. Caramez da Silva F, Justo Giugliani ER, Capsi Pires S. Duration of breastfeeding and distoclusion in the deciduous dentition. Breastfeed Med. 2012;7(6):464-8.

6. Narbutyte I, Narbutyte A, Linkevičienè L. Relationship between breastfeeding, bottle-feeding and development of malocclusion. Stomatologija. 2013;15(3):67-72.

7. Moimaz SA, Garbin AJ, Lima AM, Lolli LF, Saliba O, Garbin CA. Longitudinal study of habits leading to malocclusion development in childhood. BMC Oral Health. 2014;14:96.

8. Agarwal SS, Nehra K, Sharma M, Jayan B, Poonia A, Bhattal H. Association between breastfeeding duration, non-nutritive sucking habits and dental arch dimensions in deciduous dentition: a cross-sectional study. Progress in Orthod. 2014;15:59.

9. Victora CG, Horta BL, de Mola CL, Quevedo L, Pinheiro RT, Gigante DP, et al. Association between breastfeeding and intelligence, educational attainment, and income at 30 years of age: a prospective birth cohort study from Brazil. The Lancet Global Health. 2015;3(4):199-205.

10. Hermont AP, Martins CC, Zina LG, Auad SM, Paiva SM, Pordeus IA Breastfeeding, bottle feeding practices and malocclusion in the primary dentition: a systematic review of cohort studies. Int J Environ Res Public Health. 2015;12(3):3133-51.

11. Warren JJ, Bishara SE. Duration of nutritive and nonnutritive sucking behaviors and their effects on the dental arches in the primary dentition. Am J Orthod Dentofacial Orthop. 2002;121(4):347-56.

12. Warren JJ, Slayton RL, Bishara SE, Levy SM, Yonezu T, Kanellis MJ. Effects of nonnutritive sucking habits on occlusal characteristics in the mixed dentition. Pediatr Dent. 2005:27(6):445-50.

13. Warren JJ, Bishara SE, Steinbock KL, Yonezu T, Nowak AJ. Effects of oral habits' duration on dental characteristics in the primary dentition. J Am Dent Assoc. 2001;132(12):1685-93.

14. Bhat SS, Rao HA, Hegde KS, Kumar BK. Characteristics of primary dentition occlusion in preschool children: an epidemiological study. Int J Clin Pediatr Dent. 2012;5(2):93-7.

15. Karjalainen $\mathrm{S}$, Rönning $\mathrm{O}$, Lapinleimu $\mathrm{H}$, Simell O. Association between early meaning, non-nutritive sucking habits and occlusal anomalies in 3-year-old Finnish children. Int J Paediatr Dent. 1999;9(3):169-73.

16. Luz CL, Garib DG, Arouca R. Association between breastfeeding duration and mandibular retrusion: a cross-sectional study of children in the mixed dentition. Am J Orthod Dentofacial Orthop. 2006;130(4):531-4.

17. Vázquez-Nava F, Quezada-Castillo JA, Oviedo-Trevino S, Saldivar-González AH, Sánchez-Nuncio HR, Beltrán-Guzmán FJ, et al. Association between allergic rhinitis, bottle feeding, non-nutritive sucking habits and malocclusion in the primary dentition. Arch Dis Child. 2006;91(10):836-40.

18. Wang XT, Ge LH. Influence of feeding patterns on the development of teeth, dentition and jaw in children. Beijing Da Xue Bao. 2015;47(1):191-5.

19. Sum FH, Zhang L, Ling HT, Yeung CP, Li KY, Wong HM, et al. Association of breastfeeding and three-dimension dental arch relationships in primary dentition. BMC Oral Health. 2015:15(1):30.

20. Limeira AB, Aguiar CM, de Lima Bezerra NS, Câmara AC. Association between breast-feeding duration and posterior crossbites. J Dent Child (Chic). 2015;81(3):122-7.

21. Aznar T, Galán AF, Marín I, Domínguez A. Dental arch diameters and relationships to oral habits. Angle Orthod. 2006;76(3):441-5.

22. Ogaard B, Larsson E, Lindsten R. The effect of sucking habits, cohort, sex, intercanine arch, widths, and breast or bottle feeding on posterior crossbite in Norwegian and Swedish 3-year-old children. Am J Orthod Dentofacial Orthop. 1994;106(2):161-6.

23. Serra-Negra JMC, Pordeus IA, Rocha Júnior JF. Study of the relationship between infant feeding methods, oral habits, and malocclusion. Rev Odontol Univ São Paulo. 1997;11(2):79-86.

24. Freire GLM, Ferrari JCL, Percinoto $C$. Association between maternal breastfeeding and the development of non-nutritive sucking habits. RGO, Rev Gaúch Odontol. 2015;63(2):139-44.

25. Albuquerque SSL, Duarte RC, Cavalcanti AL, Beltrão EM. The influence of feeding methods in the development of nonnutritive sucking habits in childhood. Cien Saude Colet. 2010;15(2):371-8. 
26. Ferreira FV, Marchionatti AM, Oliveira MDM, Praetzel JR. Association between duration of breastfeeding and its influence upon the development of harmful oral habits. Rev Sul-Bras Odontol. 2010;7(1):35-40.

27. Aarts C, Hörnell A, Kylberg E, Hofvander Y, Gebre-Medhin M. Breastfeeding patterns in relation to thumb sucking and pacifier use. Pediatrics. 1999;104(4):e50

28. Thomaz EB, Cangussu MC, Assis AM. Maternal breastfeeding, parafunctional oral habits and malocclusion in adolescents: a multivariate analysis. Int J Pediatr Otorhinolaryngol. 2012;76(4):500-6

\section{Submit your manuscript to a SpringerOpen ${ }^{\circ}$ journal and benefit from:}

- Convenient online submission

- Rigorous peer review

- Immediate publication on acceptance

- Open access: articles freely available online

- High visibility within the field

- Retaining the copyright to your article

Submit your next manuscript at $>$ springeropen.com 